\section{A Historical and Contemporary \\ Discussion of the Tourism Industry in the Appalachian Region of the United States, with an analysis on its economic and sociological effects}

Nick Tarpey

Junior, Geography/Urban Studies

\section{The Region}

Appalachia is defined as a roughly 1,000-mile long region in the eastern United States nestled in and around the Appalachian mountains. It is roughly 205,000 square miles and contains all or parts of twelve states: Alabama, Georgia, Mississippi, Kentucky, Maryland, New York, Pennsylvania, Virginia, North Carolina, Tennessee, West Virginia, and Ohio. The area was home to about 25 million people as of the 2010 census. It is important to note that the region has struggled with outmigration since the 1930s beginning with the onset of the Great Depression. (Appalachian Regional Commission 2017).

Historically, Appalachia has been known as a unique region in the United States. Beginning with roots as a common settlement region for fiery Scotch-Irish immigrants in the 1700 s, continued by earning a reputation as a center for moonshine production during the 1930s, and now known as a region where the wealthy buy their second and third homes, the region has consistently been able to craft its own, particular culture. With a population that is $42 \%$ rural (compared to a $20 \%$ rural population for the entire U.S.) and overwhelmingly Scotch-Irish in ethnic composition, the area differs from the mainstream US. Beset by poverty, the region needs tourism to be a viable industry in many of its locales. A population that is relatively low in educational achievement (Appalachia as whole averages a $22 \%$ college completion rate per county compared with a US rate of $29 \%$ per county) and does not have easy access to intellectual resources in many places needs a stable, job-providing industry (Appalachian Regional Commission 2017). The area once had a legacy in the mining and forestry industries, but according to the Appalachian Regional Commission, that era has passed and people now rely on a rebirth of manufacturing, service industries, and tourism to provide jobs (2017). Fortunately, the situation in Appalachia has improved since 1960, as the number of economically distressed counties in the region has declined from 295 in 1960 to 91 in 2014 (Appalachian Regional Commission 2017). The poverty rate of $17.1 \%$ is slightly above the national average of $14.3 \%$ (Appalachian Regional Commission 2017).

The region has come to increasingly depend on the tourism industry to fill an economic void as gaps in basic services and the continual draining of potential intellectual capital from population loss continue to plague the area. This paper will examine contemporary perspectives on tourism in the Appalachian region and analyze their economic and sociological effects.

\section{A Review of Pre-1980s Appalachian Tourism:}

Tourism in the Appalachian region has taken many forms. Most people would find it surprising that it is actually one of the oldest and most-historic tourism regions in the United States. The mountainous region has been seen as a place of escape from the hustle and bustle 
of American life for generations from the Revolutionary War period through today.

In its ideological infancy, the mystique of Appalachia provided a great backdrop to serve as an incubator for the US's previously-thriving health tourism industry. From the early 1800s through the early 1900s (pre World War I), mountain springs and smaller resorts tucked away in the Appalachian Mountains served as places where people could go to escape and restore their health (Martin 2007). Attracting a mostly wealthy crowd, smaller resorts in Tennessee, North Carolina, Virginia, and West Virginia were thought of as summer refuges to escape the heat and mosquitos of lowlands and more-urban areas in an era before air conditioning and insect repellant. Summer hotels attracted these people to live in the region for a period of several months if they could afford such a second residence. Similarly, many mountain springs in the area were thought to have healing properties that attracted people from all over the eastern half of the United States as a form of medicinal therapy. In an era where ailments such as tuberculosis, hepatitis, and other infectious diseases ran rampant with minimal treatment options, springs with healing properties and misty, cool mountain oases were often seen as effective last-resort options. These could be seen as treatment options as well as vacations from one's busy life in the city (Martin 2007). Many of these resorts attempted to create an elite, Victorian feeling that was an early place-creation mechanism in an area that often served as an "escape" from daily American life. Scientifically-confirmed accounts of higher mineral counts in certain mountain streams were quoted and utilized in advertisements and distribution pamphlets by these hotels. For example, the city of Asheville, North Carolina used its cool, mountainous location and statistics proving that the city had some of the lowest rates of lung disease in the US to promote itself as a destination for those seeking a treatment for debilitating breathing ailments (Martin 2007).

The Appalachian mountains were seen as an area that was markedly cleaner and purer than the rest of a rapidly industrializing America. Breathing in cool 'Tennessee Smokies" air was often seen as "luxury" that only those with the means to travel there could experience (Martin 2007). Many of these resorts took on the moniker of "sanitarium" as a means to promote themselves as departures from usual rural lodging accommodations offered in America at the time. Hotel and lodging operators in the late 1800s also played on the Antebellum and Romantic literary movements in America (Martin 2007). Many people seeking an escape from city life to see the breathtaking views and tranquility that only "Nature" could provide came out to remote, luxury-filled resorts in the Southern and Central Appalachian region. The clientele for tourism in the Appalachian region during this time consisted mostly of well-to-do, Anglo-Saxon types from the east coast and southern cities such as Knoxville and Richmond that could access the region by the nation's rail network (Martin 2007).

The decline of the hydrotherapy and sanitarium tourism industries in the Appalachian Region, particularly in the region's southern throes, had large-scale negative economic consequences. Beginning in the post-Civil War period, many of the Southern, previously-slaveholding elites that journeyed to the well-to-do spas and sanitariums were either dead or were strapped 
for cash due to the war and emancipation (Martin 2007). The tourism industry of the pre-Civil War era was a significant chunk of Appalachian economic activity, with entire towns often existing off of a few hotels or mineral spas that catered to the rich. The loss of this elite, healing-oriented business hurt the tourism and overall economic environment of the region, but this was later counterbalanced by an increase in people coming to seek general respite from their busy urban lives for the cooler, slower-paced mountain locales (Martin 2007). Most of these types of resorts and tourism activities began to decline in the period after World War I due to a general increase in the health of the American population because of improvements in public health, including vaccinations. As trains and later automobiles changed the accessibility of the American landscape, a more socioeconomically diverse crowd was able to come and enjoy the natural wonders of Appalachia, not just the extremely elite of Southern society. Towns in the region began to regain their economic benefits from mountain-escape tourism towards the end of the 19th century, but it never returned to the previous levels in terms of percentage of GDP of the region (Martin 2007).

The establishment of the Great Smoky Mountains National Park and the creation of national roads and highways in the early 1900s changed the trajectory of tourism in the region. The Great Smoky Mountains National Park was the first major "destination" spot in the region aimed at attracting as many tourists as possible. Local businesses and villages came to depend on this feature attraction in a multi-county area. The greater accessibility of Appalachian locales and the increasing income diversity of tourists that entered the region (as more and more people could afford automobiles) shifted the focus in Appalachia from a luxury, Romantic industry to one that was more set on creating places and experiences for a wider audience. Numerous road programs created by the Federal government as well as local roads-improvement authorities vastly improved the quality of the region's roads from the turn of the twentieth century through World War II. And after World War II, the Federal Highways Act put forth by the Eisenhower administration changed the way people travel not just in Appalachia, but all across America (Martin 2007).

The creation of the Blue Ridge Parkway starting in the early 1900s served as an early infrastructural piece and 'conceived historical site' developed by the Federal government intended to promote specific locales for people to visit. The Federal government promoted the idea of Appalachia as a hardworking, blue-collar, pioneer-era region by eliminating any signs that did not reflect this along the Blue Ridge Parkway route and constructing farmhouses, shops, and other identifiers of setting (e.g., wooden fences) in their place where visitors could stop and peek into a blacksmith's shop along their drive, for example. It wasn't necessarily the most accurate picture of how most Appalachians lived at the time, but it was an image the government created to spur economic development in the region (Martin 2007).

The image of place-creation began to switch as the century progressed. Rather than create a positive, hardworking image of Appalachians, other private tourism ventures began to display Appalachian people as "hillbillies" and their attractions completely played up this negative image of Appalachian people as uneducated, slow, and lazy people 
that took joy in pleasures such as making moonshine and wearing straw hats. The ability to market Appalachian distinctiveness as something immensely profitable was realized. This unique folk image of Appalachia was supported by cultural and anthropological studies that took an interest in the region that has supposedly been isolated from the broader American culture since people of European descent originally began settling the area in the 1600s (Martin 2007). As an isolated people, their cultural mannerisms and distinct way of life were seen as something that should be seen and experienced. The issue with this is that many spurious sociological claims and stereotypes were mistakenly blended with this tourism experience. As outside hands began to meddle with the area's tourist attractions, the majority of tourist destinations in the region were one-stop points for people to come, stay, consume some element of watered-down culture, and then leave. Examples of these types of attractions include theme parks such as Dollywood (in Tennessee, arguably the modern tourism capital of Appalachia), country-music halls, outlet malls, indoor skydiving parks, helicopter rides, and gambling (Martin 2007). A startling development also occurred in the postwar era with regards to Appalachian tourism. Many well-to-do Southern elites introduced myriad elements of the Dixie, "rebel" lifestyle to the Appalachian region, an identity that did not necessarily fit with the area's historical identity. For example, in the 1960s, one could travel to Tennessee and see a Civil War re-enactment (with the Confederates winning) in a backwater region that actually supported the Union army. But in an era where southern elites controlled the money and subsequent tourist attractions in an area that was being visited by clientele that were mostly
Southern, Anglo-Saxon people seeking out a "pure" and "white" tourism environment that differed from the rest of the "darkening" of the US during the Civil Rights era, this is what was unfortunately created to keep the region economically viable (Martin 2007). During this period, the Appalachian Region served as a different kind of escape for tourists. The rural region was a departure from the progressive, changing attitudes of the rest of the US.

\section{A Change in the Tourism Environment: 1980-now}

A refreshing change has been witnessed in the Appalachian tourism industry starting around the last thirty years. There has been a shift towards ideas of heritage and more authentic cultural tourism. While the tacky, artificial-place tourism remains popular in Tennessee and North Carolina, other areas of Appalachia have certainly attempted to distance themselves from this economically distant, socially difficult, and environmentally unsustainable method of economic development. Chaney (2017) discusses how a new, yet also historically significant, element in the Appalachian Tourism narrative (the idea of the "Crooked Road," a larger metaphor that is also a literal historic road in Appalachia) is a byproduct of new American consumer tastes that can be applied to areas that go beyond tourism. Chaney (2017, p.141) argues that "the appeal of a cultural and affective alternate route--an alternative to high speed, rootless, globalized landscape of mass consumption" is an ideal that has proven to be viable in the modern American consumptive landscape. The idea of the Crooked Road--an alternate, winding, somewhat broken path, has gained traction as Americans have developed a craving for authenticity, 'living history,' and an 
experience of culture as opposed to an escape to a place (Chaney 2017). This is where the ethnic, natural, and historical uniqueness of the Appalachian region can become a competitive advantage in the tourism industry. For example, the town of Point Pleasant, West Virginia, on the Ohio River, has completely branded itself as a destination providing the perfect view of daily life in Appalachia. The town utilizes historical events such as a 1967 bridge collapse in the town that killed 45 people, a local legend known as the Mothman, who is a

Boogeyman-like figure that is linked to the bridge collapse, a farming museum, multiple "living history" museums, outdoor recreation opportunities, and a quaint downtown that embraces a hardy Appalachian spirit to conjure an image of Appalachia that is appealing to an out-of-towner (Kruse 2015).

All of these elements aren't necessarily one singular attraction, but serve as a backdrop to a general place that offers a slice of culture through an experiential lens. It is the new era of tourism in the region, where one doesn't necessarily have to spend money in Dollywood in order for the larger area to be economically alive. People can come in to Point Pleasant, stay at local hotels, and choose from a diverse array of different activities, all while immersing themselves in a particular settlement (Kruse 2015). This type of tourism is more sustainable because it is much more ingrained with the current local economy and local environmental footprint than a theme park or resort build-up. This type of tourism tends to draw a more "steady-stream," consistent crowd as well. Rather than seek out people with sums of disposable income, many Appalachian towns are branding themselves as convenient getaway locales for weekend or multi-day excursions that can be fit in with many budgets (Kruse
2015). This is convenient for busy families that desire family-friendly activities that are more of an enrichment as opposed to an escape. Many state tourism boards promote the fact that most places in Appalachia are within a day's drive of many of the metropolitan areas on the East Coast and in the Great Lakes (Fristch and Johannsen 2004). The new-age tourist attractions are also compatible with the increase in the numbers of heritage-education buffs and families that seek a deeper desire to understand their heritage better, which constitute a small but relatively economically-significant segment of visitors to Appalachia's small towns (Lalone 2005). Many people in the United States have roots in Appalachia that have since been severed as families have moved away seeking greater economic prosperity.

The educational and enrichment potential that Appalachian tourism has should not be overlooked. Seen as an alternative to traditional museums and education locales such as Washington, D.C., the creation of museums of living history and past industry are rapidly increasing in the region and as projects are developed by locals for a more regional crowd, have the chance to remain popular for a long time (Fritsch and Johansen 2004). Coal mining heritage parks and Appalachian Civil War history parks have become more popular in recent years because of their steady ability to draw visitors and relative immunity to economic boom-bust cycles (Lalone 2005). Eller (2008) points out the continued success of local/tourist activity blending, such as the promotion of "festivals celebrating mountain music and crafts and fairs promoting local farm products, homecomings, historical reenactments, and community gatherings of all kinds." These types of events serve as rallying 
cries for their respective communities to raise morale but also represent a larger-scale chance for nonresidents to come in and experience life as an Appalachian.

In addition, the Appalachian Regional Commission and many state tourism authorities have begun reinvesting in state and national parklands and wilderness areas as the desire to experience the rural aesthetic has increased across America. As more and more people continue to leave rural life for the urban realm, the perception of rural life has changed. Once regarded as boring and for poor people, many people now desire a rural experience as "something authentic and unique in the face of an increasingly standardized and predictable urban lifestyle" (Chaney 2017, p.126). The yearning for adventure and outdoor recreation directly reflect this. Governmental authorities have stepped up in their maintenance. upkeep, and overall promotion of park areas to keep up with increasing demand and accompanying wear and tear for these natural resources. Walking parts of the Appalachian Trail, once a remote, rare tourist activity, is now seen as a popular and desirable item to cross off one's bucket list. The Appalachian Trail, an entity that stretches over 2,000 miles, runs through 14 states, and has over 3 million visitors per year, is the flagship piece of the transition to more nature-based and "new era" tourism in the Appalachian region (Appalachian Trail Conservancy 2017). Forestry expert and regional planning activist Brenton MacKaye came up with the concept of the trail in 1921, ironically as a network for city dwellers to connect with rural farms and work camps (Appalachian Trail Conservancy 2017). The trail, started as a private and volunteer entity, did not come under control of the National Parks Service until the 1960s. Completed in
1937, the trail today is much more heavily used than at its founding, and is often incorporated into roadside pit stops as people often perform brief day hikes in addition to the partial-trail and entire-trail hikes that can take upwards of seven or eight months (Appalachian Trail Conservancy 2017). The final rights-of-way along the trail were bought from private owners in the year 2014, as the subject of Federal land acquisition was often a bitter issue among longtime residents of Appalachia that did not want to see Federal or "city-dwelling" interference with their properties. The Federalization of the Appalachian Trail that came about in the 1960s catapulted it into the cultural icon that it is today and also sparked other nature and conservation-based tourism initiatives in the region such as the much more aggressive marketing and upkeep of existing Federal lands such as Great Smoky Mountains National Park (est. 1934) and Shenandoah National Park (est. 1935) that are arguably the two flagship Federal lands in the Appalachian region (US National Parks Service 2017). This new, intense promotion of tourism from a conservationist or "natural" lens was seen as a way to jumpstart the lackluster economies of Appalachia that became more evident and destitute after the second World War.

Another way to experience the natural aesthetic of the Appalachian region is through driving. Although not as popular in recent decades after the Federal Interstate Highways Act of 1956 carved massive, visually boring thoroughfares through the region's weathered terrain, side roads and other alternate routes remain popular with those that enjoy breathtaking views and up-close visits to charming, rural small towns that dot the sparsely populated backcountry landscapes of Appalachia (Visit Appalachia 2017). The Blue 
Ridge Parkway, mentioned previously, has historically been the most famous of these routes. A Federally owned road, it stretches almost 500 miles through Virginia and Appalachia. Other popular driving routes include the Historic National Road in Ohio and Pennsylvania, the Midland Trail in West Virginia, the Southern Highroads Trail in Georgia and Tennessee, and the Tales and Trails route in Tennessee and Virginia (Visit Appalachia 2017). All of these routes combine the throwback nature of slow driving tours, stopping to sightsee and enjoy rural life, while also being in the comfort of a car and having the ability to stop at a hotel or motel whenever the tourists please along the way.

On the more commercialized side of things, ziplining and whitewater rafting have seen major developments over the past few decades, particularly in Virginia and West Virginia. Overall, people within a day's drive of many of these locales are seeking thrill and adventure that they just cannot find in the city. Many of these people are younger and poorer than the average tourist, so they can only stay for a limited amounts of time and do not provide as much of a yearned-for "multiplier effect" as families or more-traditional leisure tourists. Due to the fact that many of these new-age tourists may be spending less, there is a hope that local tourism officials can entice greater numbers of them to come to offset their individual visit monetary losses. As an increasing amount of people become "re-Romanticized" with the environment and natural surroundings, there has been a greater desire to go out and experience these resources in a relatively environmentally conscious way such as through camping and/or hiking (Fritsch and Johannsen 2004).

\section{Host-Guest Issues of Appalachia Tourism}

Many of the host-guest issues relating to Appalachian tourism have been improved upon in recent decades. However, some still remain critical issues, and new issues that have potential for developing into key conflicts between hosts and guests have emerged. In many of the popular places for people to visit Appalachia, where some of the more traditional methods of tourism have thrived, such as Gatlinburg, Tennessee, the home of Dollywood, cultural misappropriation has arisen as a critical issue. Many Northern and East Coast visitors to these sites have misunderstood that Appalachia in itself should not be characterized right alongside the Deep South. Both places are culturally, linguistically, and economically different. Many tourists in the area come in with assumptions and expectations that the area will be similar to the Deep South (Martin 2007). Many times, this is appropriate due to the tourism environment that is created (Martin 2007). People's expectations are often that Appalachia will be some intense rebel hideaway (it is often far from the case), and a visitor's misunderstanding of this sociological fact can cause unneeded friction. Other times, this can cause conflict due to a misunderstanding between the visitor and a local resident.

$$
\text { Relatedly, host and guest issues have }
$$
been reported between people that just seek to see the natural beauty of many Appalachian locales without acknowledging the people that live there. Treating Appalachian people like they do not exist, that only the land they inhabit matters and the individual people do not, eliminates any type of context that someone would have from visiting some type of natural formation or historical site and it serves as a commodification that strips individuals of their 
value. This issue has certainly manifested itself in the rise of second-home-building in Appalachia (Martin 2007). Cheap land and easier accessibility have prompted many wealthy individuals to build retirement homes on premier land in the region. Many of these wealthy people do not interact with the community (although the community may benefit from their property tax payments). Additionally, their massive holdings often raise property values in certain areas and have the effect of pushing longtime landowners out in a form of rural gentrification because they cannot afford to pay increased rents and/or taxes. Relatedly, it is crucial to note that Appalachia during this time period serves as a microcosm of American life at the beginning of the $21 \mathrm{st}$ century that is a cruelly ironic but accurate way of illustrating what our society is beginning to look like socioeconomically. The interesting dynamic between the newfound crowds of suburban and urban "hip" and "yuppie" tourists into the area to "renew" their relationship with the natural and historic aspects of the US coexists alongside a slow but steady exodus of similarly-aged young people that are leaving these mountainous regions for the cities that these yuppies currently inhabit in search of a better life (Eller 2005).

This mirrors the struggle between urban business executives who crave rights-of-way and large plots of land to develop housing and tourist attractions and the local families who have been in the area for generations, living out of the same double-wide trailer, that do not like seeing visitors who prompted more regulation in town and have erected "ugly" fencing or "no trespassing" signs. Many of these visitors do not understand the fetishization of coal in a region where it sometimes employed one half of a county's workforce in some particular areas. Many times, there is a gap in perspectives between the visitor and the host in this situation because there is literally no shared living experience. Heritage tourism and town/location-based tourism have a chance to alleviate some of these issues, though it should be acknowledged that this is a tall order.

The immigrant experience, especially in the tourism industry of the region, can sometimes be distorted and be a cause for unnecessary alarm by tourists. Despite the fact that general American notions and most stereotypes would say that the immigrant experience is nonexistent in a place such as Appalachia, the immigrant experience is definitely a cultural attribute of the region. Spanish, Chinese, Venezuelan, and Indian immigrant communities are all present in various Appalachian towns, either as a majority or a strong minority (Cowdery 2010). Many visitors will travel to Appalachia and be surprised or taken aback to see a person of nonwhite racial composition working a ticket booth, cleaning a restroom, or managing a gas station, to name examples of how the immigrant experience can be manifested into the general American tourist experience. These immigrant enclaves not only struggle with fitting in daily with the communities they inhabit, but also with visitors to the area that may not be expecting, accustomed to, or desiring any type of immigrant experience while on a visit to Appalachia (Cowdery 2010).

There is a dual host-guest issue confronting immigrants working in Appalachian Region tourism. There is a "defense of place-based culture and community, which goes against many of the dominant themes of sharing culture and being culturally competent and aware in this day and 
age" (Smith 2012, p.237) that runs rampant in Appalachia, distorting or even eliminating possible perceptions of the "melting pot" image of America in many locales. A key sticking point is that many immigrant workers often compete with the 'native' or 'white' workers for jobs in the tourism sector. Being that the tourism industry is often a last-resort option for many in communities with heavy industrial, blue-collar, decent-paying job losses, competition for these low-skill and low-wage jobs that are vital to many families is extraordinarily intense; survival for familial socio economic livelihood is fierce (Smith 2012).

\section{Conclusion}

Appalachian tourism has come a long way since being the preference of wealthy Victorian-esque elites and Dixiecrats seeking an escape. The tourism palette of the area has diversified ideologically and socioeconomically, presenting an array of activities and peoples that appeal to fatter shares of the American market. The potential for Appalachian tourism to rise in prominence exists. It is becoming a more sustainable industry, with more green measures and minimal impact activities. It is becoming more culturally sound, appealing to a broad swath of the American public through heritage and industrial ruins sites. It has responded well to changing consumer tastes and economic constraints, becoming more in-line with the transient, service-oriented economies of the new age. Many of the tourism activities are designed to accommodate part time or unusual work schedules, making the Appalachian a viable option for many Americans. The area is accessible to a large population and its attractions blend well with one of the longest-running American narratives, the automobile (Fritsch and Johannsen 2004).

However, questions do remain about Appalachian tourism. Certain host-guest issues remain pressing. How do you create an authentic cultural experience without invading a local resident's privacy? How do you overcome the contrast in the economic viability of the visitors versus that of the local residents? What can be done to alleviate the discomfort that currently defines the immigrant experience in the region's tourism industry? Questions of sustainability still need to be answered. Where do tourism bureaus draw the line in encouraging people to visit parks and wilderness areas? Surely local residents and visitors alike do not want to visit washed-up and overused natural resources. Lastly, there needs to be questions asked on how the Appalachian region assimilates with the rest of the United States. While it is important to acknowledge that the region will grow and change as the mass media and telecommunications markets only extend their reaches, it needs to be recognized that regional "improvement" does not need to be associated with becoming cosmopolitan. In an era of increasing globalization, Appalachia needs to stand its ground as an area that is rich in cultural and folk tradition, one that is mostly separated and distinct from the rest of the US (Fritsch and Johannsen 2004). While promoting itself, the region needs to preserve its identity while also improving the quality of life for its people, a regrettably tough balancing act. 
Appendix A: Map of counties defined as "Appalachian Region" by the Appalachian Regional Commission and their level of economic status (Appalachian Regional Commission 2017).

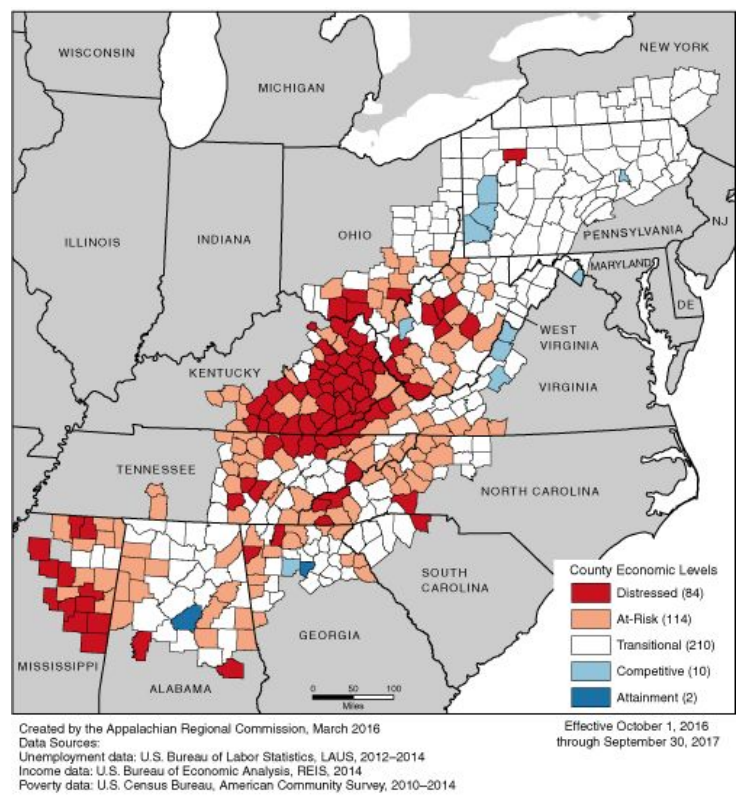




\section{References}

Appalachian Regional Commission 2017, , The Appalachian Region [Homepage of Appalachian Regional Commission], [Online]. Available:

https://www.arc.gov/appalachian region/T heAppalachianRegion.asp [2017, 4/25].

Appalachian Trail Conservancy 2017, , History of the Trail [Homepage of Appalachian Trail Conservancy], [Online]. Available: http://www.appalachiantrail.org/home/abo ut-us/history [2017, 4/29].

Chaney, R. 2017, "“'Heritage" as alternative place and space: old-time music and rootsand routes-based tourism in Southern Appalachia", Journal of Heritage Tourism, vol. 12 , no. 2 , pp. 125-138.

Cowdery, J.R. 2010, "Immigrants in appalachia: Educational implications for meeting the needs of all children", International Journal of Multicultural Education, vol. 12, no. 1.

Eller, R.D. 2008, Uneven Ground; Appalachia since 1945, University Press of Kentucky.

Fritsch, A. \& Johannsen, K. 2004, Ecotourism in Appalachia: Marketing the Mountains, First edn, University of Kentucky Press, Lexington.

Kruse,Robert J.,,II 2015, "Point Pleasant, West Virginia: making a tourism landscape in an Appalachian Town", Southeastern Geographer, vol. 55, pp. 313+.

LALONE, M.B. 2005, "AN

ANTHRO-PLANNING APPROACH TO LOCAL HERITAGE TOURISM: CASE STUDIES FROM APPALACHIA", NAPA Bulletin, vol. 23, no. 1, pp. 135-150.
Martin, C.B. 2007, Tourism in the Mountain South: A Double-Edged Sword, First edn, The University of Tennessee Press, Knoxville.

SMITH, B.E. 2012, "The Price of the Ticket: Latino Immigrants and the Challenge of Community in Appalachia", Appalachian Journal, vol. 39, no. 3, pp. 234-244.

US National Park Service 2017, , Appalachian [Homepage of US National Park Service], [Online]. Available:

https://www.nps.gov/appa/index.htm [2017, 4/29].

Visit Appalachia 2017, , Driving Tours [Homepage of Visit Appalachia], [Online]. Available: http://visitappalachia.com/driving-tours/ [2017, 4/29]. 